\title{
Simulation and Optimization of Cooling Tubes of Transformer for Efficient Heat Transfer
}

\author{
Jackwin Vincent K, Dr V.V.Prathibha Bharathi
}

${ }^{1}$ Department of mechanical Engineering, Malla Reddy college of Engineering, Secunderabad, India

\begin{abstract}
Temperature variation with in the transformer affects the life and efficiency of the distribution transformer. The top oil temperature in the transformer depends on the type of cooling and cooling ducts/fins design and their layout. The present project investigates methods of onan transformer cooling system by means of increasing heat transfer rate by implanting the axial groves along with fins and porous region within in the cooling tubes and further optimization of the cooling process by adjusting the gravity by orienting the tube. This study is carried out by means of numerical analysis by simulating Transformer geometry in Ansys Fluent .Real case geometry of distribution transformer is used in this simulation
\end{abstract}

Keywords- Ansys Fluent, CFD, Distribution transformer cooling, numerical Analysis, Optimization

\section{INTRODUCTION}

There are several factors contributing to power losses in transformers. These are copper losses, which represent the major source of losses in a transformer, and core losses; namely hysteresis and eddy current losses. These losses components are produced in the form of heat energy which should be dissipated in a quick and rather efficient manner. If the transformer has otherwise failed to get rid of such heat generated, many problems could arise and in some cases severe consequences may occur.

In fact, the improperly dissipated heat would further accumulate and thus cause the transformer temperature to increase. This process may lead to failure of paper insulation and liquid insulation medium of the transformer. Furthermore, excessive heat may result in damage of the transformer windings, the matter which, in particular, is considered as a catastrophe for expensive high power rating transformers. Therefore, numerous ways are introduced to keep the temperature within acceptable limits which in turn would help to maintain a long lifetime of the transformer. One such way is onan cooling of transformer which means oil natural air natural which is in distribution transformer. This method makes use of natural convection of transformer oil and air.

The present project investigates methods of transformer cooling system by means of increasing heat transfer rate by implanting the axial groves along with fins and porous region within in the cooling tubes. And further optimization of the cooling process by adjusting the gravity by orienting the tube. Five optimization cases is studied This study is carried out by means of numerical analysis by simulating Transformer geometry in Ansys Fluent.

An experimental investigation of Temperature distribution in a distribution transformer and Experiment investigation of free convection heat transfer from an array of vertical tube is carried out by A.Satyanarayana.Reddy, Suresh Akella, and AMK. Prasad [1][2].Thermal modeling of natural convection cooled oil immersed distribution transformer is carried out by Robert Michael Marko[3]. Transformer cooling system improvement has been extensively studied through analytical or advanced numerical techniques by Miguel E. Rosillo[5]. Eleftherios I. Amoiralis and Stefan D.L. ŢĂLU [4] developed a method for optimum transformer tank panels geometry for the cooling system. Y. X. Wang, H. B. Ma and G. P. Peterson [6] did Investigation of the Temperature Distribution on Radiator Fins with Micro Heat Pipes.

S.A.Nada and M.Mowad [7] performed an experimental study on free convection from a vertical and inclined semicircular cylinder at different orientations at constant heat flux. The experiments were carried at four inclination angles $\left(0^{\circ}, 30^{\circ}, 45^{\circ}\right.$ and $\left.60^{\circ}\right)$ of the semicircular cylinder. The results showed that the average Nusselt number increases as the inclination angle of the semicircular cylinder increases. Alegi, g. and Black simulated Realtime thermal mode1 for an oil immersed forced-air cooled transformer. They contributed the study of forced convection in the area of distribution transformer.

\section{IMPROVEMENT OF TRANSFORMER COOLING SYSTEM}

The transformer consists of a closed magnetic circuit (the core) with two coils, or windings, of insulated conductors wound around the core. The current in the input, or primary, coil creates a magnetic field. This field induces a voltage across the output, or secondary coil. The secondary coil of a distribution transformer is designed to deliver energy at a lower level of voltage relative to the input voltage. For a distribution transformer, the high 
voltage winding is the primary coil and the low voltage winding is the secondary coil.

As the current passes through the copper or Aluminum windings, energy is lost because of electrical resistance power losses (Power $=$ current $2 \times$ Resistance). The energy losses raise the temperature of the windings. Various methods of dissipating energy to the surroundings are employed to cool the windings. The temperature rise is controlled by transferring energy generated from the transformer to a cooling fluid, such as oil or air. Excess heating accelerates the aging of the transformer insulation.

When the oil paper insulation is subjected to thermal stress, the oil and paper components of the insulation may be irreversibly damaged. The thermal stress reduces the mechanical and dielectric performance of the insulation .There is a need to optimize the design and application of transformers. Manufacturers and utilities try to reduce the capital and operational costs of transformers. The main objectives of this Project are:

- Numerical simulation of natural convection process in a onan distribution transformer and find out maximum hot spot temperature at the core and windings

- To carry out design optimization in cooling tubes to increase heat transfer and to reduce hot spot temperature of core.

- Comparative study of five optimization cases for efficient heat transfer

- Case 1: normal case without any modification

- Case 2: Implanting axial grooves with fins in cooling tubes

- Case 3: With porous media inside cooling tubes

- Case 4: With porous media and axial grooves with fins inside tubes.

- Case 5: With inclination of cooling tubes

\section{NUMERICAL SIMULATION AND OPTIMIZATION}

The fluid flow and heat transfer in a transformer is modeled in this work using the Navier-Stokes equations for incompressible flow, and the conservation of energy equation. The mathematical mode1 used in the thesis consists of four equations: energy conservation, momentum conservation, and mass conservation. The solution of the energy equation produces the temperature field, and the momentum equations determine the velocities in the fluid. The mass conservation equation ensures that fluid entering a control volume also leaves the control volume and is used as the constraint on pressure. The energy conservation equation is given by Equation (1). The first term on the left hand side of the energy conservation equation represents the energy storage. The second and third terms represent the advection of energy by the moving fluid. On the right hand side of the equation, the first three terms are the energy diffusion term and the last term represents the energy generation per unit volume.

'Cp $\partial) / \partial \mathrm{t}(\rho \mathrm{T})+\mathrm{Cp} \partial / \partial \mathrm{x}(\rho \mathrm{UT})+\mathrm{Cp} \partial / \partial \mathrm{y}(\rho \mathrm{VT})+\mathrm{Cp} \partial / \partial \mathrm{z}$ $(\rho \mathrm{WT})=\partial / \partial \mathrm{x} \mathrm{Kx} \partial \mathrm{T} / \partial \mathrm{x}+\partial / \partial \mathrm{y} \mathrm{Ky} \partial \mathrm{T} / \partial \mathrm{y}+\partial / \partial \mathrm{z} \mathrm{Kz} \partial \mathrm{T} / \partial \mathrm{z}^{+} \mathrm{Q}^{\prime}$ (1)

The momentum conservation equations in three dimensions, Equations (2) (3), (4) are used to calculate the velocity fields. The first term in each equation represents the change in momentum over the time. The second, third and fourth terms on the left hand side of the equations represent the advection of momentum. The first three terms on the right-hand side of the equations account for the net viscous forces, and the fourth term represents the pressure forces. The last term of the $y$ direction momentum equation represents the buoyancy force used when solving a natural convection problem.

$\partial / \partial \mathrm{t}(\rho \mathrm{U})+\partial / \partial \mathrm{x}(\rho \mathrm{UU})+\partial / \partial \mathrm{y}(\rho \mathrm{VU})+\partial / \partial \mathrm{z}(\rho \mathrm{WU})=\partial / \partial \mathrm{x} \mu$ $\partial \mathrm{U} / \partial \mathrm{x}+\partial / \partial \mathrm{y} \mu \partial \mathrm{U} / \partial \mathrm{y}+\partial / \partial \mathrm{z} \mu \partial \mathrm{U} / \partial \mathrm{z}-\partial \mathrm{P} / \partial \mathrm{x}$

$\partial / \partial \mathrm{t}(\rho \mathrm{V})+\partial / \partial \mathrm{x}(\rho \mathrm{UV})+\partial / \partial \mathrm{y}(\rho \mathrm{VV})+\partial / \partial \mathrm{z}(\rho \mathrm{WV})=\partial / \partial \mathrm{x} \mu$ $\partial \mathrm{V} / \partial \mathrm{x}+\partial / \partial \mathrm{y} \mu \partial \mathrm{V} / \partial \mathrm{y}+\partial / \partial \mathrm{z} \mu \partial \mathrm{W} / \partial \mathrm{z}-\partial \mathrm{P} / \partial \mathrm{y}+\rho_{\infty \propto \beta \mathrm{g}\left(\mathrm{T}-\mathrm{T}_{\infty)}\right.}$ (3) $\partial / \partial \mathrm{t}(\rho \mathrm{W})+\partial / \partial \mathrm{x}(\rho \mathrm{UW})+\partial / \partial \mathrm{y}(\rho \mathrm{WW})+\partial / \partial \mathrm{z}(\rho \mathrm{WW})=\partial / \partial \mathrm{x}$ $\mu \partial \mathrm{W} / \partial \mathrm{x}+\partial / \partial \mathrm{y} \mu \partial \mathrm{W} / \partial \mathrm{y}+\partial / \partial \mathrm{z} \mu \partial \mathrm{W} / \partial \mathrm{z}-\partial \mathrm{P} / \partial \mathrm{z}$

Natural convection is the body force driving fluid flow within a naturally oil cooled transformer. A buoyancy force is the net effect of body forces acting on a fluid in which there are density gradients. For this model, the density gradient is induced by a temperature gradient in the fluid, and the body force is due to the gravitational field, $\mathrm{g}$, acting in the negative $\mathrm{x}$ direction.

The buoyancy force in the momentum equation is modeled by using the Boussinesq approximation .In that term, $\rho_{-} \infty$, is the average fluid density, $\beta$ is the thermal coefficient of volume expansion, and $T_{-} \infty$, is the average fluid temperature. Equation (5) is the continuity equation. In that equation the first term accounts for the mass storage, and the other three terms describe the change of mass flow in both $\mathrm{x}, \mathrm{y}$ and $\mathrm{z}$ directions, respectively.

$(\partial) / \partial \mathrm{t}(\rho)+\partial / \partial \mathrm{x}(\rho \mathrm{U})+\partial / \partial \mathrm{y}(\rho \mathrm{V})+\partial / \partial \mathrm{z}(\rho \mathrm{W})=0$

The mathematical model consists of a set of differential equations expressing conservation of mass, momentum, and energy, over a Cartesian domain. The fluid was assumed to have Newtonian and laminar -Turbulent flow characteristics. The energy equation was modified to allow for conjugate heat transfer between a solid and the surrounding fluid. A method for modeling the windings as a homogeneous material was also introduced. The transport equations were discretized using a finite volume 
approach, and the pressure-velocity coupling was handled using the SIMPLE algorithm.

\subsection{CFD analysis using Ansys Fluent}

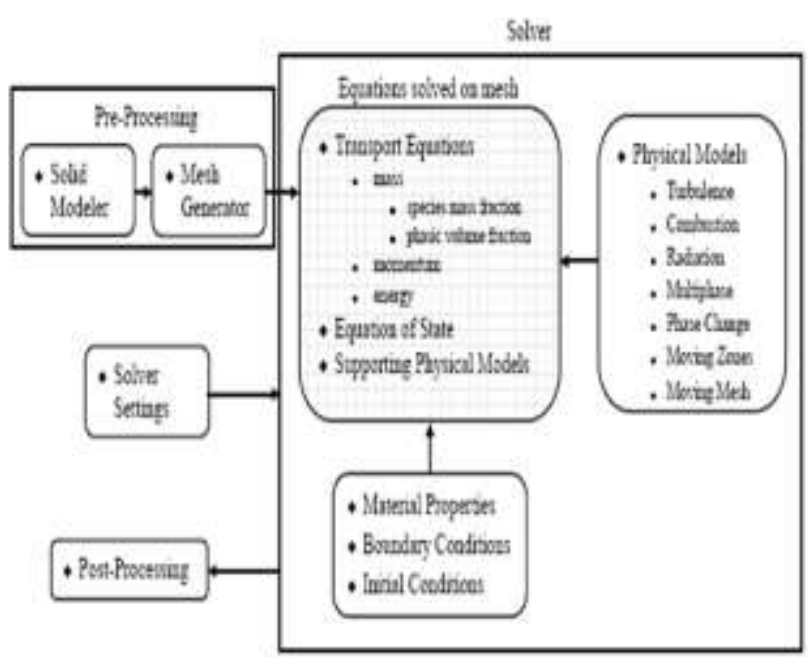

Fig 1: General process of CFD analysis

\subsubsection{Preprocessing \& Solver set up}

Geometry considered for analysis is that of an ONAN distribution transformer (oil natural air natural).Model contains a source, oil tank, cooling transformer oil, oil collecting region and cooling tubes or radiators. Source includes copper windings and coil. Major heat is dissipated from the source due to eddy current loss and copper loss and heat transfer occur due to convection, conduction and radiation.

As Transformer is oil immersed to provide cooling by natural convection, major heat transfer is occurred by convection, so heat transfer by conduction and radiation is negligible and neglected from Analysis. Geometry is created using CatiaV5 R20.

Meshing is done in ANSYS ICEM CFD, with minimum skewness of 0.82 .Maximum face size is $6 \mathrm{~mm}$ and maximum size is $12 \mathrm{~mm}$. Minimum edge length is $2 \mathrm{~mm}$. Meshing is defined as discretizing the cad model into finite element model. Simulation is done in Ansys Fluent .Before 2006 Fluent is a separate solver, now Ansys acquired Fluent and is within the Ansys workbench module .Open the Setup option of Ansys fluent project

- $\quad$ Select Solver setup > General > among solver settings choose the pressure based solver. CFD fluent consist of two solvers for solving the CFD process i.e. pressure based and density based. Here we choose pressure based; this is because the fluid is incompressible. Choose the velocity formulation as absolute and time option as steady state. This is because flow is considered to have constant properties with respect to time.

Select Solver setup > Models > Choose energy equation on.. To solve the heat transfer problems the basic energy equation has to be used and this can be used by switching on the energy equation. Transition K-KLomega model is one of the most commonly used turbulence models to model Transition flow. It is a three equation model that means, it includes three extra transport equations to represent the turbulent properties of flow. The K-KL-omega transition model is used to predict boundary layer development and calculate transition onset. This model can be used to effectively address the transition of the boundary layer from a laminar to a turbulent regime. The K - KL -omega model is considered to be a three-equation eddy-viscosity type, which includes transport equations for turbulent kinetic energy (K_T), laminar kinetic energy (K_L), and the inverse turbulent time scale $(\omega)$.

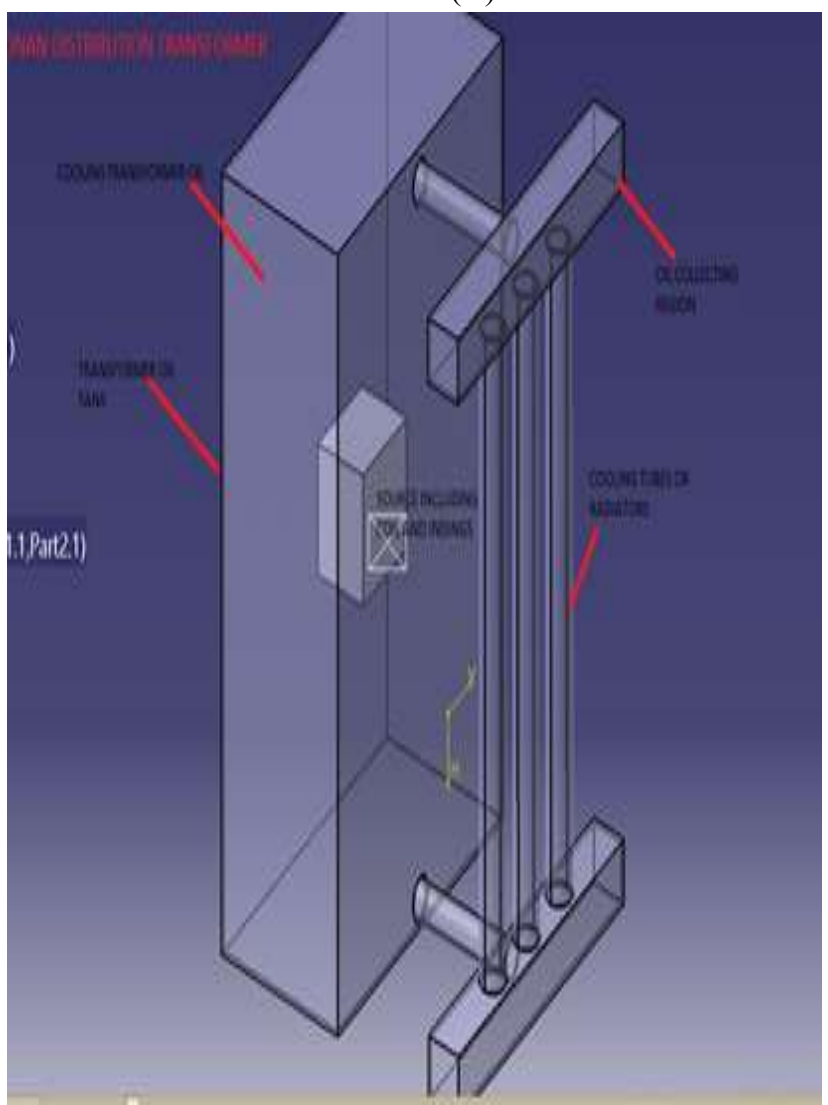

Fig 2: Catia model used in the analysis 


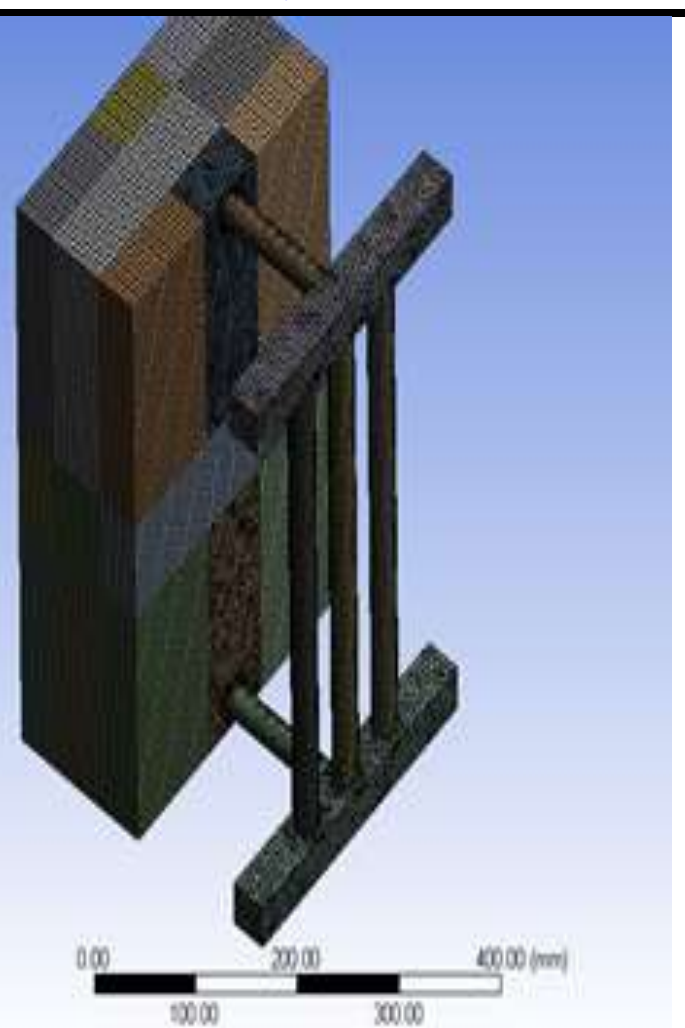

Fig 3: Meshed model

Select Cell zone conditions and choose the appropriate materials for the zones. Transformer oil is defined to fluid zone. Copper is assigned to part-source and in source terms Energy source of $1302082 \mathrm{w} / \mathrm{m}^{\wedge} 3$ is defined to represent energy generation in core. In part- porous domain switch on the porous zone to model corresponding case if not uncheck the option. In the solution method choose pressure velocity coupling scheme as SIMPLE.

SIMPLE is the acronym of semi implicit method for pressure linked equations. It is the default scheme and the robust one which can be used for all types of analysis. Choose the gradient option as 'least square cell based'. It is the default method; has the good accuracy and the same time it is computationally less intensive. Choose body force weighted option for the pressure. It is used for gravity has prominent role. Choose momentum, turbulent kinetic energy and laminar kinetic energy and specific dissipation rate and energy as first order upwind.

Select the monitors $>$ residuals. Click edit. In the dialogue box that appears edit the convergence criteria of continuity, $\mathrm{x}$ velocity, $\mathrm{y}$ velocity, $\mathrm{z}$ velocity, $\mathrm{k}$, Omega as 0.001. Energy as 0.000001 Close the dialogue box.

In the solution initialization select the hybrid initialization and click initialize. By starting CFD simulation we must provide fluent with an initial guess for the solution flow field. Hybrid initialization is a collection of recipes and boundary interpolation methods. It solves Laplace's equation to determine the velocity and pressure fields. All other variables, such as temperature, turbulence, species fractions, volume fractions, etc., will be automatically patched based on domain averaged values or a particular interpolation recipe. In the Run calculation window edit the number of iterations as 10000 and click calculate. Within 500 iterations solver will give the converged results with required accuracy.

Table.1: Material properties used

\begin{tabular}{|c|c|c|}
\hline Materials & Transformet oll & Cepper \\
\hline $\begin{array}{l}\text { Density } \\
\mathrm{kg}^{\prime} \mathrm{m}^{3}\end{array}$ & $\begin{array}{l}\text { Polynomial function with two } \\
\text { coefficients and variable as } \\
\text { temperature Developed frum } \\
\text { Boaninesq approximation } \\
\qquad p=p(1-\beta \Delta T) \\
\text { Coefficient } 1=893 \\
\text { Coefficient } 2=0.69654\end{array}$ & 8978 \\
\hline $\begin{array}{l}\text { Specific } \\
\text { heat } j \mathrm{kgzK}\end{array}$ & 2060 & 381 \\
\hline $\begin{array}{l}\text { Thermal } \\
\text { conductivi } \\
\text { ty wimk }\end{array}$ & 0.12 & 387.6 \\
\hline $\begin{array}{l}\text { Viscosity } \\
\mathrm{Kg} / \mathrm{mad}\end{array}$ & .024111 & Not applicalie \\
\hline
\end{tabular}

Table 2: Boundary conditions

\begin{tabular}{|c|c|c|c|}
\hline Boundary mall & $\begin{array}{c}\text { Type of boundary } \\
\text { condition }\end{array}$ & Momentum Tab & Thermal Tab \\
\hline Adiabatic & Wall & $\begin{array}{l}\text { Wall motion as } \\
\text { stationary wall } \\
\text { Shear condition as no } \\
\text { slip }\end{array}$ & $\begin{array}{l}\text { Thermal condition } \\
\text { heat flux } \\
\text { Heat flux - } 0 \text { wim2 } \\
\text { Material-Copper }\end{array}$ \\
\hline Heat flux-pat-oil & Wall & $\begin{array}{l}\text { Wall motion as } \\
\text { stationary wall } \\
\text { Shear condition as no } \\
\text { slip }\end{array}$ & $\begin{array}{c}\text { Temperature }=300 \mathrm{~K} \\
\text { Material-copper }\end{array}$ \\
\hline $\begin{array}{l}\text { Heat flux-part- } \\
\text { porous domain }\end{array}$ & Wall & $\begin{array}{l}\text { Wall motion as } \\
\text { stationary wall } \\
\text { Shear condition as no } \\
\text { slip }\end{array}$ & $\begin{array}{l}\text { Temperature }=300 \mathrm{~K} \\
\text { Material-copper }\end{array}$ \\
\hline $\begin{array}{l}\text { Wall-part-cil-part- } \\
\text { scurce }\end{array}$ & Wall & $\begin{array}{l}\text { Wall motion as } \\
\text { stationary wall } \\
\text { Shear condition as no } \\
\text { sip }\end{array}$ & $\begin{array}{c}\text { Thermal condition is } \\
\text { coupled } \\
\text { Material-Copper }\end{array}$ \\
\hline $\begin{array}{l}\text { wall-part-oil-part- } \\
\text { source-shadow }\end{array}$ & $\mathrm{W}_{2} \mathrm{II}$ & $\begin{array}{l}\text { Wall motion as } \\
\text { stationary wall } \\
\text { Shear condition as no } \\
\text { slip }\end{array}$ & $\begin{array}{l}\text { Thermal condition is } \\
\text { coupled } \\
\text { Material-Copper }\end{array}$ \\
\hline
\end{tabular}




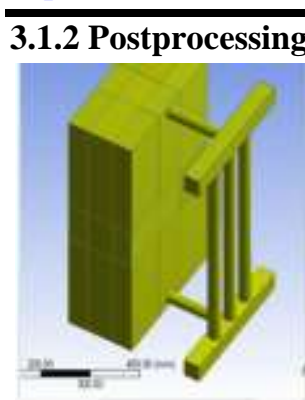

Case 1

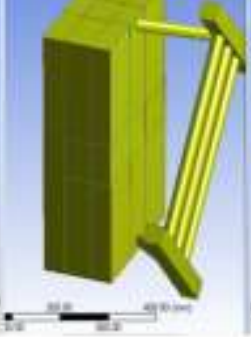

Case 5

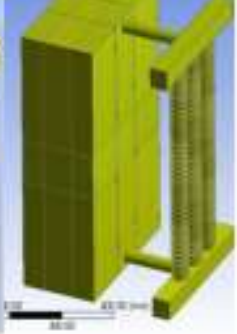

Case 3

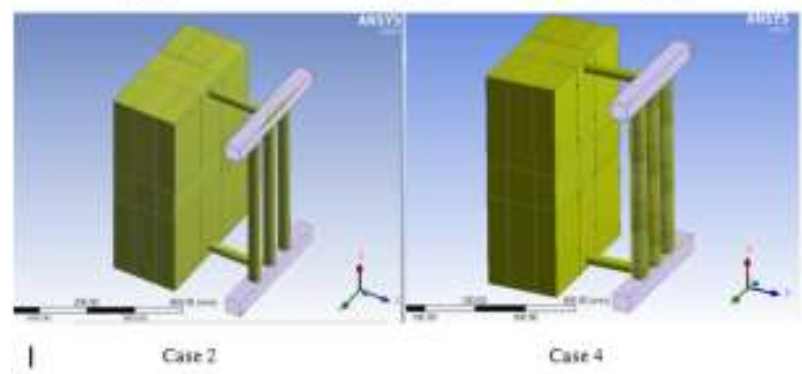

Fig.4: Geometry of different cases used in the analysis

IV. RESULTS AND OBSERVATIONS

Table.3: Values of output variables for all cases

\begin{tabular}{|c|c|c|c|c|}
\hline \multirow[t]{2}{*}{ Case } & \multicolumn{4}{|c|}{$\begin{array}{l}\text { Masimum \& Minimam Values Of Output Variables } \\
\text { (Location: Out Plane at 0.148 m from zx plane of Transformer model, } \\
\text { Domain: All domains) }\end{array}$} \\
\hline & $\begin{array}{l}\text { Temperature } \\
\text { (k) }\end{array}$ & $\begin{array}{l}\text { Velocity } \\
\text { ms }\end{array}$ & $\begin{array}{c}\text { Turbulence } \\
\text { kinetic energy } \\
\text { jkg }\end{array}$ & $\begin{array}{l}\text { Turbalence } \\
\text { edaty frequency } \\
s^{-1}\end{array}$ \\
\hline Case 1 & $\begin{array}{l}\text { Max: } 390.1 \\
\text { Min: } 300\end{array}$ & $\begin{array}{l}\text { Max: } .04852 \\
\text { Min: } \quad .004852\end{array}$ & $\begin{array}{l}\text { Max: } 1 \\
\text { Min: } 0007049\end{array}$ & $\begin{array}{l}\text { Max: } 0.989 \\
\text { Sin: } 0.8206\end{array}$ \\
\hline Case 2 & $\begin{array}{l}\text { Max: } 356.6 \\
\text { Mfn: } 300\end{array}$ & $\begin{array}{l}\text { Max: } 04874 \\
\text { Min: } \quad 004874\end{array}$ & $\begin{array}{l}\text { Max: } 1 \\
\text { Min: } 001847\end{array}$ & $\begin{array}{l}\text { Sax: } 0.9955 \\
\text { Bin: } 0.9144\end{array}$ \\
\hline Case 3 & $\begin{array}{l}\text { Max: } 364.1 \\
\text { Min: } 300\end{array}$ & $\begin{array}{l}\text { Mas: } .06413 \\
\text { Min: } .006413\end{array}$ & $\begin{array}{l}\text { Max: I } \\
\text { Min .002217 }\end{array}$ & $\begin{array}{l}\text { Max: } 0.9922 \\
\text { SIm: } 0.8509\end{array}$ \\
\hline Case 4 & $\begin{array}{l}\text { Max: } 3865 \\
\text { Min: } \quad 300\end{array}$ & $\begin{array}{l}\text { Max: } 06882 \\
\text { Min: } \quad 006882\end{array}$ & $\begin{array}{l}\text { Max: } 1 \\
\text { Min: } 8.881 e^{-14}\end{array}$ & $\begin{array}{l}\text { Max: } 0.9838 \\
\text { Min: } .005237\end{array}$ \\
\hline Rase 5 & $\begin{array}{l}\text { Max } 431.5 \\
\text { Mfr: } 300\end{array}$ & $\begin{array}{l}\text { Nax: } .07958 \\
\text { Min: } \quad 007958\end{array}$ & $\begin{array}{l}\text { Max: } 1 \\
\text { Min: } 2537 e^{-13}\end{array}$ & $\begin{array}{l}\text { Max: } 0.9800 \\
\text { Man: } \quad 05237\end{array}$ \\
\hline
\end{tabular}

\subsection{Temperature contours}
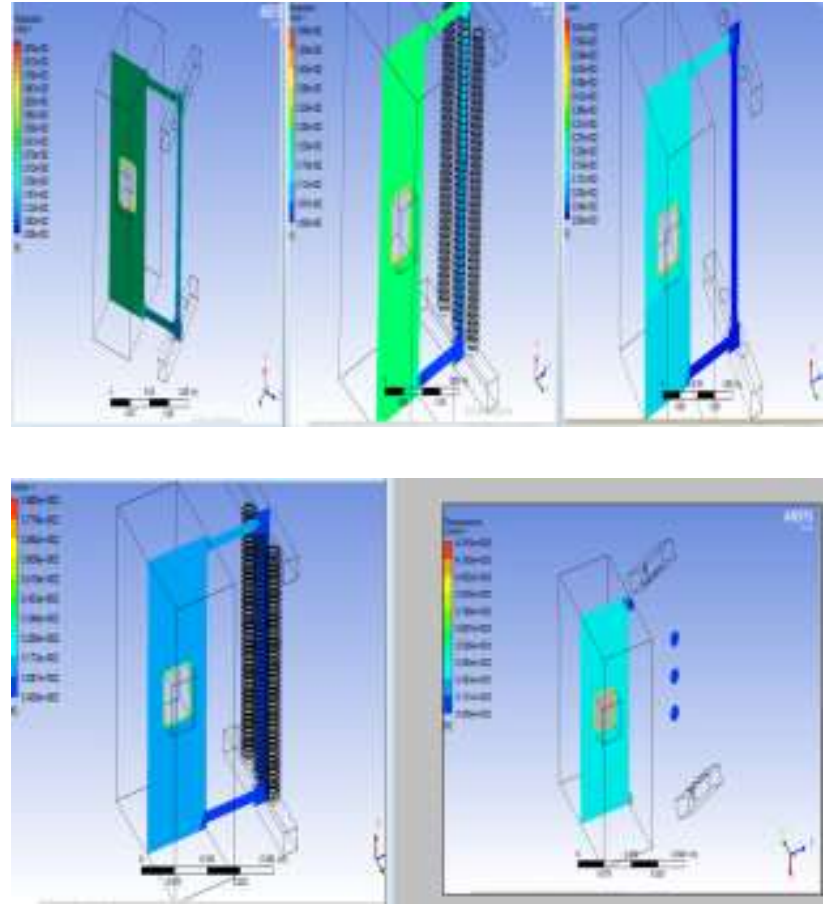

Fig: 5: Temperature contour for all 5 cases

\subsection{Graph comparing Results}

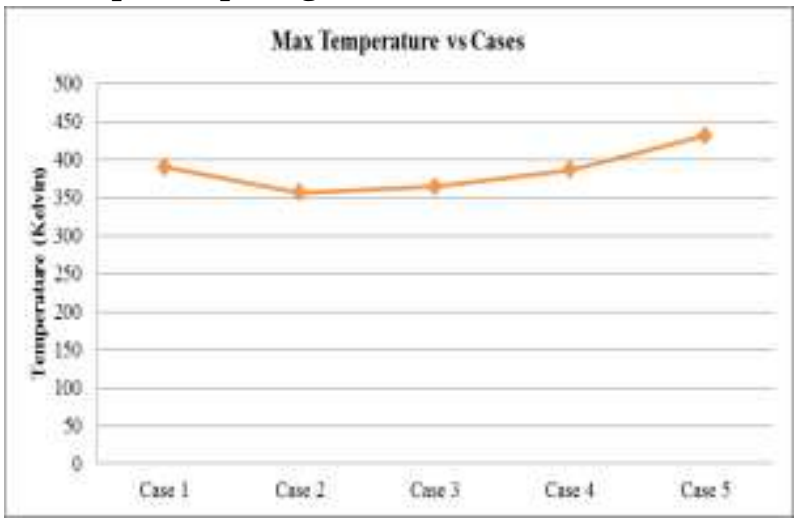

Fig.6.Graph showing max temperature vs all cases

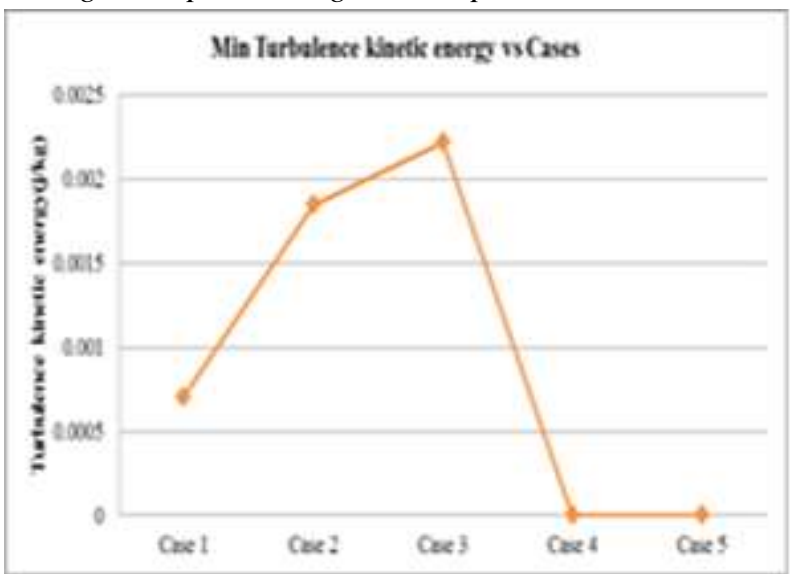

Fig.7: Graph showing turbulence kinetic energy vs all cases 


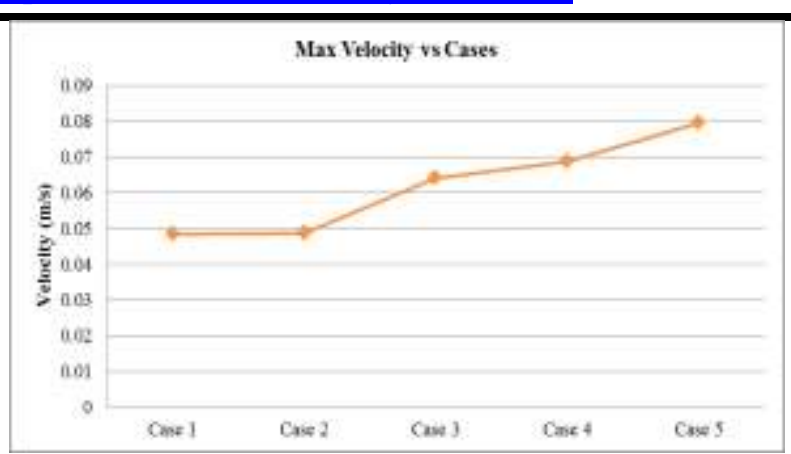

Fig.8: Graph comparing different velocities

\section{CONCLUSION}

Numerical simulation of free convection in onan distribution transformer is done and a mixed laminar and turbulent flow is found to be occurred, also design modification in cooling tubes provides better turbulent generation and increased heat transfer. Cooling tube with axial grooves and fins are found to be most effective by decreasing hot spot temperature by 34 degree Celsius .Also from the simulation it is found that natural convection flow of transfer oil due to density difference with increase in temperature can be effectively simulated using computational fluid dynamics.

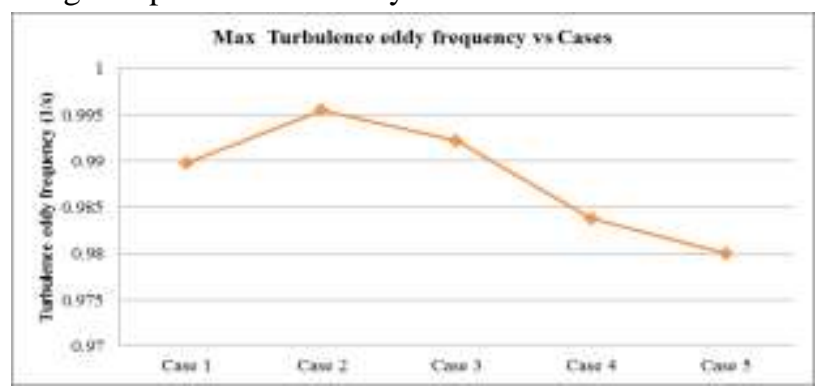

Fig.9: Graph comparing Turbulence eddy frequency vs cases

\section{REFERENCES}

[1] International Journal of Emerging Technology and Advanced Engineering ISSN 2250-2459, ISO 9001:2008 Certified Journal, Volume 4, Issue 3, March 2014) 253Experimental Study of Free Convection Heat Transfer From Array Of Vertical Tubes At Different Inclinations by A.Satyanarayana.Reddy, Suresh Akella, AMK. Prasad

[2] Vol. 3 Issue 4, April - 2014 International Journal of Engineering Research \& Technology (IJERT) ISSN: 2278-0181 Investigation of the Temperature Variation in Distribution Transformer Cooling System by A.Satyanarayana.Reddy, Suresh Akella, AMK. Prasad

[3] Thermal Modeling of a Natural-Convection-Cooled, Oil-Immersed Distribution Transformer by Robert Michael Marko.
[4] Ştefan D.L. ȚĂLU1, Mihai D.L. ȚĂLU2Dimensional optimization of frontal radiators Of cooling system for power transformer $630 \mathrm{Kva}$ 20/0.4 kv in terms of maximum heat transfer, U.P.B. Sci. Bull. Series C, Vol. 72, Iss. 4, 2010

[5] Miguel E. Rosillo, Carlos A. Herrera, and Guillermo Jaramillo, IEEE Transactions On Power Delivery, Vol. 27, No. 4, October 2012

[6] Y. X. Wang, H. B. Ma and G. P. Peterson Investigation of the Temperature Distribution on Radiator Fins with Micro Heat Pipes, Journal Of Thermo physics And Heat Transfer ,Vol. 15, No. 1, January-March 2001

[7] S. A. Nada a and M. Mowad, Free convection from a vertical and inclined semicircular cylinder. 